\title{
OPTIMAL DESIGN OF IN-SITU PERMEABLE REACTIVE BARRIER
}

\author{
SHASHI MATHURA \& PRATIKSHA PANDEYB \\ Department of Civil Engineering, Indian Institute of Technology Delhi, India
}

\begin{abstract}
The study provides a methodology of obtaining optimal design parameters of Permeable Reactive Barriers (PRB) through a multi-objective optimization problem involving the cost and time of remediation. A PRB is an in-situ eco-friendly remediation technology that comprises reactive material that helps remove heavy metals and petroleum hydrocarbons from groundwater. A numerical model is developed in the study to solve the contaminant transport equation that is validated and thereafter used to simulate cases of contamination due to heavy metals. Subsequently, the required length and width of the continuous reactive barrier are determined from the plot of maximum relative concentrations. The impact of various hydraulic parameters on the design parameters as well as the cost of PRB is then studied following which the maximum length and width of the barrier as well as the total cost to clean up is determined. A similar exercise is further conducted for BTEX contaminated site after validating the developed model. A PRB is placed at varying distances from the source of pollution and the corresponding length, width and time for remediation computed. Following this, a multi-objective algorithm is developed to minimize the two objectives namely: the cost and time for remediation. Two different Hybrid algorithms are developed combining various algorithms and a set of Paretos of cost and time of remediation for different population sizes is computed using Artificial Neural Networks (ANN). The performance of the algorithms is then analysed using two performance analysers. A set of optimal solutions for the length, width, distance of barrier from the source and the corresponding cost and time of remediation are subsequently computed.
\end{abstract}

Keywords: permeable reactive barrier, heavy metals, BTEX, ANN, contamination, optimization.

\section{INTRODUCTION}

Heavy metals including zinc $(\mathrm{Zn})$, arsenic $(\mathrm{As})$, lead $(\mathrm{Pb})$, cadmium $(\mathrm{Cd})$, nickel $(\mathrm{Ni})$, cobalt $(\mathrm{Co})$, iron $(\mathrm{Fe})$, chromium $(\mathrm{Cr})$, iron $(\mathrm{Fe})$, silver $(\mathrm{Ag})$ etc. are naturally found in geologic parent materials or rocks. These metals exist in groundwater sometimes at levels greater than the permissible limits. In the present study, an attempt has been made to remove the excess amount of $\mathrm{Zn}$ from groundwater using advanced numerical modelling. A review of literature shows that heavy metals from the subsurface domain have been removed through various mechanisms that include adsorption (Morrison and Spangler [1]), precipitation (McMurtry and Elton [2]) and biological treatment (Kurniawan et al. [3]). Similarly, Babel and Kurniawan [4] found that zero valent iron is a very popular adsorbent that could help remove $\mathrm{Zn}$ from the groundwater if placed within the permeable reactive barriers (PRBs).

To simulate any groundwater management problem, there exists a need to couple the simulation model with optimization tools. Conventionally, groundwater management problems are solved either by generating several simulation runs (Hunt et al. [5]; Budge and Sharp [6]) or by choosing different optimization tools (Mantoglou [7]; Gaur et al. [8]). However, a combined approach of simulation-optimization model is now in trend (Cheng et al. [9]; Vedula et al. [10]). Many researchers have adopted such a combined methodology for a pump and treat system and through optimization, attempted to minimize the cost as well as the remediation time needed to reach the goal (Ko et al. [11]). In the present study, a simulation model is replaced with a neural network simulator which is thereafter coupled with an advanced multi-objective optimization approach to optimize the cost as well as the 
time of remediation needed by permeable reactive barrier for complete restoration and management of BTEX contaminated groundwater. Since the past two decades, instead of using a real simulator, several models (Neural Network, Support Vector Machine etc.) have been adopted by researchers to reduce the computation burden. Neural network has been used widely in the area of water resources (Aziz and Wong [12]) and thus used in this study as a proxy simulator.

\section{GOVERNING EQUATIONS}

The partial differential equation of flow and transport of solute is solved assuming the aquifer is homogeneous and isotropic under a steady head with flow in one direction only. The governing three-dimensional equations for steady state flow (eqn (1)) in one direction yields the velocity that is substituted in the two-dimensional mass transport equation (eqn (2)) to compute the spatial and temporal concentration of the contaminant (Rifai et al. [13]).

$$
\begin{gathered}
\nabla^{2} \varphi=0 \\
\frac{\partial S}{\partial t}=\frac{1}{\mu_{c}}\left[L_{x} \frac{\partial^{2} S}{\partial x^{2}}+L_{y} \frac{\partial^{2} S}{\partial y^{2}}-w \frac{\partial S}{\partial x}\right]-\frac{S_{s} W^{*}}{T \eta_{e}}
\end{gathered}
$$

In the above equations, $\varphi$ represents the head $(\mathrm{m}) ; S$ is the concentration of solute $\left(\mathrm{M} / \mathrm{L}^{3}\right)$; $\eta_{e}$ is effective porosity of the aquifer; $w$ is the flow velocity in the $\mathrm{x}$ direction $(\mathrm{L} / \mathrm{T})$; $L_{x}$ and $L_{y}$ are the coefficients of hydrodynamic dispersion $\left(\mathrm{L}^{2} / \mathrm{T}\right)$ in $x$ and $y$ directions respectively; and $\mathrm{t}$ is time (T); $S_{s}$ is the concentration of solute in the source $\left(\mathrm{M} / \mathrm{L}^{3}\right)$; $\mathrm{T}$ is the saturated thickness $(\mathrm{L}) ; W^{*}$ is the volume flux per unit area $(\mathrm{L} / \mathrm{T})$ and $\mu_{c}$ is the retardation factor. An alternating direction implicit (ADI) technique is used to discretize eqn (2). Further, a numerical 2D code was developed using MATLAB programming and named MAT2D. After developing MAT2D using the ADI technique, the model is next validated with the results of Wilson and Miller [14]. The model is simulated for 365 days and the results (Fig. 1) obtained using MAT2D and Visual MODFLOW are found to be in close agreement with that of Wilson and Miller [14].

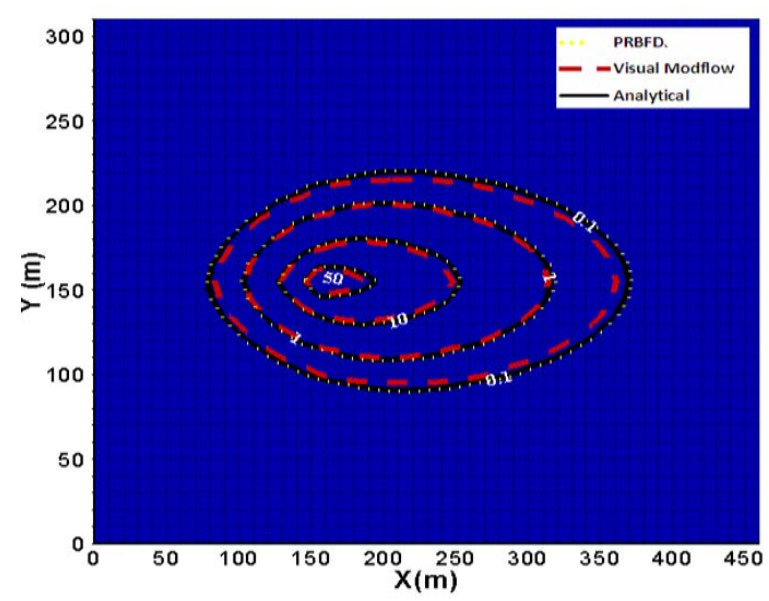

Figure 1: Comparison of analytical and numerically modelled concentration. 


\section{METHODOLOGY AND RESULTS}

The validated model MAT2D is next applied to a site of size $150 \mathrm{~m}$ wide and $300 \mathrm{~m}$ long with east and west sides of the aquifer at constant heads at $75 \mathrm{~m}$ and $73.5 \mathrm{~m}$ respectively. The flow is from west to east at a hydraulic gradient of 0.005 . Fig. 2 depicts the plan view of the site and indicates the location of the source of contamination as well as the flow boundary conditions. The thickness of the aquifer is $5 \mathrm{~m}$ and the aquifer is overlain and underlain by impervious layers. Further, the effective porosity and hydraulic conductivity of the aquifer are assumed to be 0.3 and $1 \times 10^{-4} \mathrm{~m} / \mathrm{s}$ respectively. Initially it is assumed that the concentration of metal is zero everywhere except at the location of the source where the concentration of contaminant is assumed to be a finite source of $100 \mathrm{mg} / \mathrm{l} \mathrm{spread}$ over a source area $(10 \mathrm{~m} \times 10 \mathrm{~m})$. It is also assumed that at the boundaries of the aquifer, the flux is zero.

A two-step procedure is followed and solved by MAT2D. In the first stage, natural attenuation within the aquifer (flow of metal concentration in the aquifer without any barrier) is observed for duration of 4 years. Later, a study is conducted to see the impact of placing a PRB adjacent to the source of metal contamination. Spatial and temporal variations of metal concentration for the duration of 4 years are obtained in the first stage and thereafter the maximum concentration over the entire time period is obtained by picking up peak concentration values and their locations at various times, as the contaminant moves. Following this, the maximum relative concentration is obtained for each peak concentration value and plotted in the $\mathrm{x}$ and $\mathrm{y}$ direction. In this study the maximum permissible limit of metal concentration is assumed to be 0.05 (obtained on dividing the permissible value $5 \mathrm{mg} / \mathrm{l}$ by the maximum source concentration value of $100 \mathrm{mg} / \mathrm{l}$ ). The length and width of aquifer required without any remediation measures up to a permissible limit of 0.05 in the $\mathrm{x}$ and $\mathrm{y}$ directions are found to be $100 \mathrm{~m}$ and $20 \mathrm{~m}$ respectively (Figs 3 and 4, respectively).

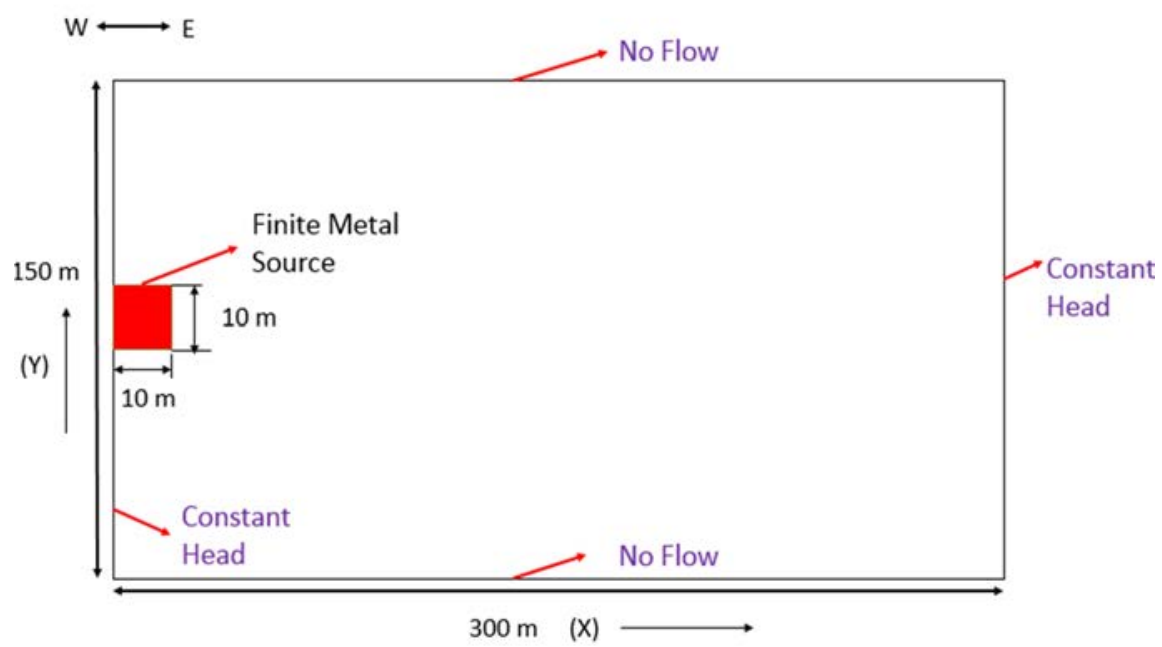

Figure 2: Schematic diagram of metal contaminated site. 


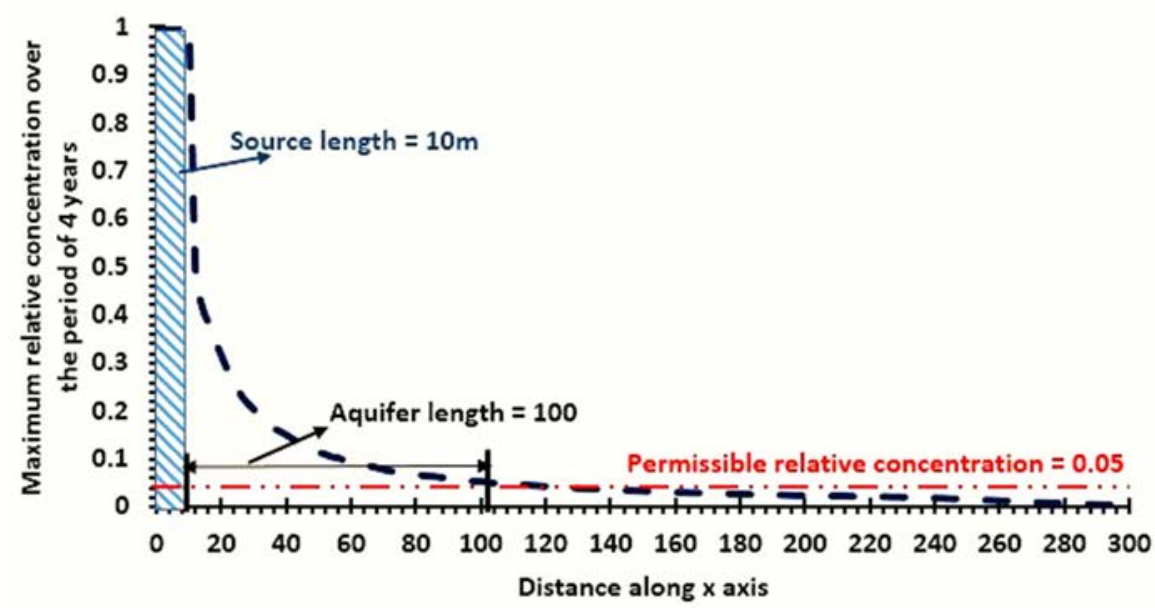

Figure 3: Length of aquifer along $\mathrm{x}$ axis for a permissible relative concentration of 0.05 .

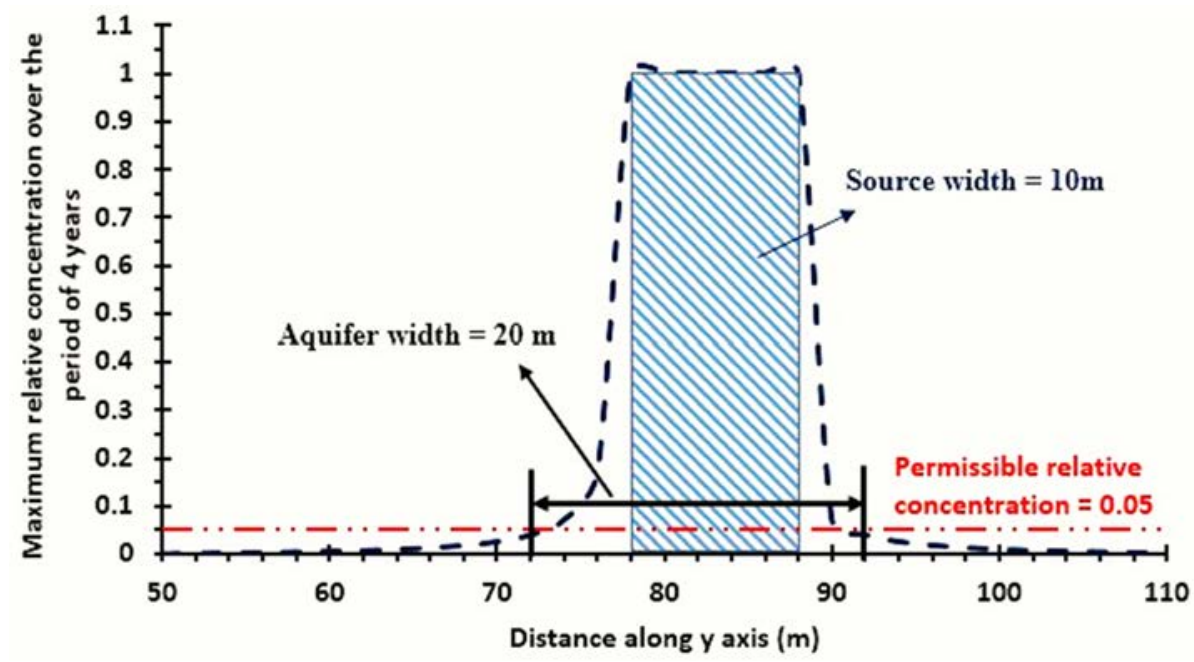

Figure 4: Width of aquifer along y axis for a permissible relative concentration of 0.05 .

The length and width of the aquifer required in the absence of any engineered remediation technique such that the permissible concentration limit of 0.05 is reached is thus very large. A continuous reactive barrier (CRB) is next placed in the aquifer such that the removal of metal concentration reaches its permissible limit in a much shorter length of aquifer. The hydraulic conductivity and retardation factor when zero valent iron (ZVI) is used as reactive material in the barrier are taken as $0.01 \mathrm{~m} / \mathrm{sec}$ and 8 respectively with an effective porosity of 0.48 (Burger and Finkel [15]).

A similar exercise as in the above case (without barrier) is repeated to obtain the maximum relative concentration when a barrier is installed in the vicinity of the source. Further, from the chart of maximum relative concentration over the duration of 4 years (Figs 5 and 6), one 
can see that the maximum length of barrier now comes out to be $24 \mathrm{~m}$ when the barrier is located adjacent the source. In case the barrier is installed at a certain distance away from the source, this length would decrease. However, in the absence of a barrier, the distance from the source to a point where the permissible concentration of $\mathrm{Zn}$ reaches $5 \mathrm{mg} / \mathrm{l}$ was earlier found to be $100 \mathrm{~m}$. Similarly the width of barrier (along the y direction) needed for a full plume capture is obtained as $16 \mathrm{~m}$, which is also small when compared to the width obtained in the absence of a barrier. Later the total installation cost of a continuous permeable reactive barrier is obtained as $€ 652,000$ using the cost function of Bürger et al. [16].

Furthermore, the impact of change in the values of hydraulic conductivity over the barrier parameters (length and width) along with the associated total installation cost is also evaluated. A change in the hydraulic conductivity of the barrier results into a change in the length and cost of the barrier.

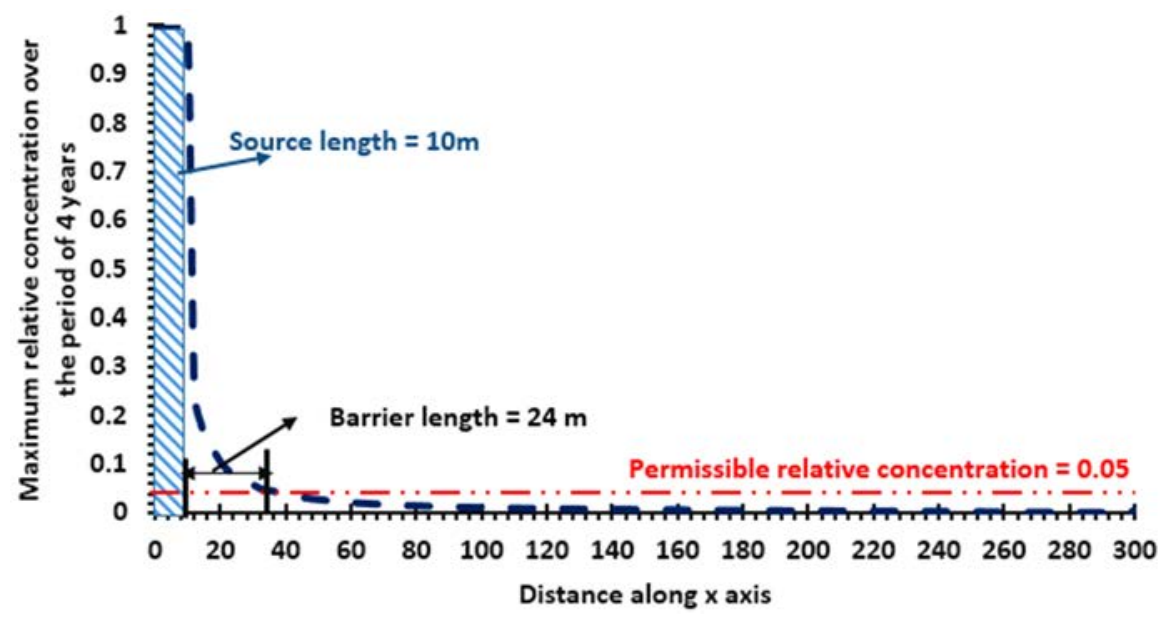

Figure 5: Barrier length for maximum relative permissible concentration of 0.05 .

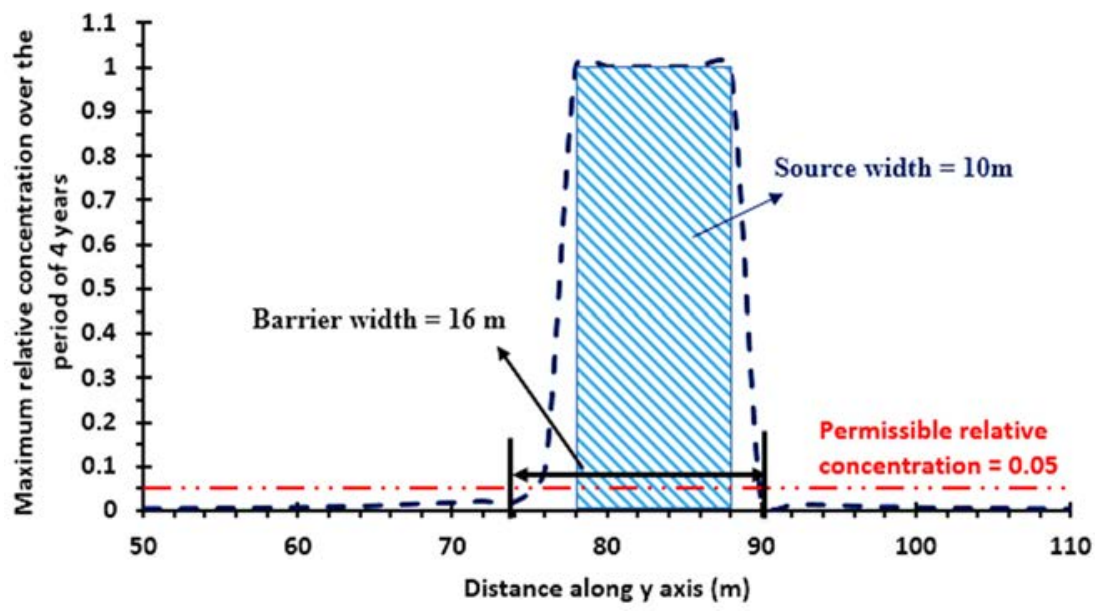

Figure 6: Barrier width for maximum relative permissible concentration of 0.05 . 
A decrease in the conductivity of the barrier results into a decrease in the length and cost of the barrier, however, the width of the barrier is found to increase with a decrease in the conductivity of the barrier.

A similar exercise is conducted to see the impact of barrier in a BTEX contaminated site. The selected study area is $200 \mathrm{~m}$ wide and $300 \mathrm{~m}$ long with an aquifer thickness of $5 \mathrm{~m}$. The east and west sides of the aquifer are subjected to constant head boundaries with upstream and downstream heads at $30 \mathrm{~m}$ and $28.5 \mathrm{~m}$ respectively, whereas the north and south domains of the aquifer are assumed to be no flow or impervious boundaries. The effective porosity and hydraulic conductivity of the aquifer material are assumed to be 0.30 and $6 \times 10^{-5} \mathrm{~m} / \mathrm{sec}$ respectively. Furthermore, it is also assumed that, BTEX contaminant enters the aquifer instantaneously at a finite concentration of $100 \mathrm{mg} / \mathrm{l}$. A monitoring well located at the point $(224 \mathrm{~m}, 108 \mathrm{~m})$ records the concentration of BTEX till the maximum allowable BTEX concentration of $1 \mathrm{mg} / \mathrm{l}$ is achieved. The longitudinal as well as the transverse dispersivity of the aquifer are taken as $10 \mathrm{~m}$ and $2 \mathrm{~m}$ respectively. A plan view of the site is shown into Fig. 7.

The fate of BTEX concentration is obtained for the maximum duration of 6 years using MAT2D and results validated with Visual Modflow model. It was found that the BTEX concentration near the monitoring well in the $6^{\text {th }}$ year is $1.92 \mathrm{mg} / \mathrm{l}$ at a location of $190 \mathrm{~m}$ in the $\mathrm{x}$ direction. A continuous permeable reactive barrier is provided so as to obtain the desired permissible concentration of BTEX at the exit face. Bowman [17] suggested that surfactant modified zeolite (SMZ) is a very good adsorbent and can be used as a permeable reactive material to sorb organic and inorganic contaminants from groundwater. Hence, SMZ is considered as the PRB material in this study. Finding an optimum location of the barrier for its placement is very difficult and a trial and error method takes a lot of time. The design parameters as well as cost and the time required for remediation depend on the location of the barrier from the pollutant source. If the barrier is located very near the source, the required length of the PRB comes out to be very large as compared to the case when it is kept far away from the source position. However, the width is inversely proportional to the length due to attainment of wider spread of plume with time. In addition to this, the time of remediation is also influenced by the location of the barrier and it may be lower if the barrier is near to source or much higher if it is installed far away from the source. Hence, one can see that if the barrier is installed very near the source, the time of remediation will very small whereas the total cost of the system will be very high and vice versa. Thus, there is a need to determine

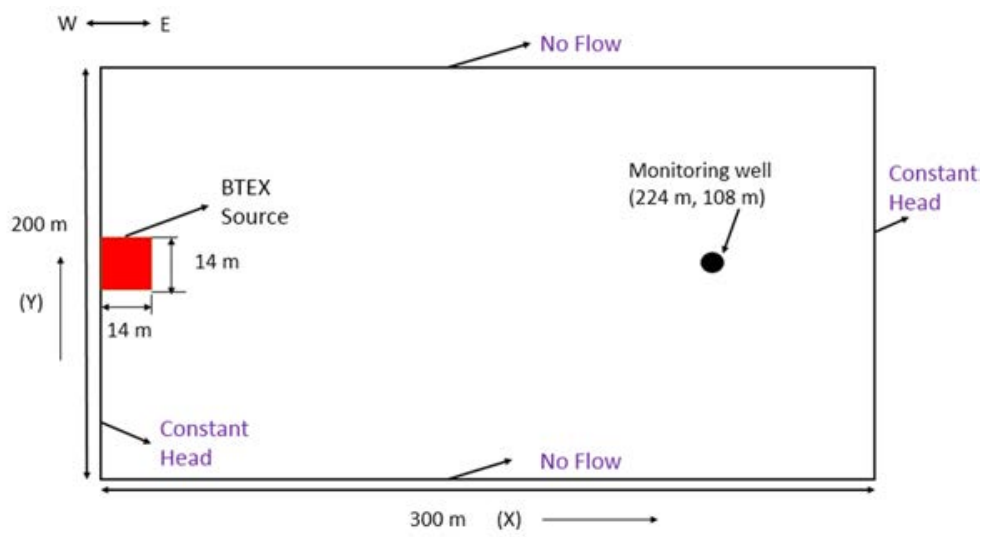

Figure 7: Plan view of BTEX contaminated site. 
an optimal location of the barrier at which the goal of minimizing the two objectives namely total design cost of the barrier as well as the time of remediation can be achieved through a multi-objective optimization.

The hydraulic conductivity of SMZ is taken to be $0.00196 \mathrm{~m} / \mathrm{s}$ and the partitioning coefficient $\left(\mathrm{K}_{\mathrm{d}}\right)$ is $17 \mathrm{~L} / \mathrm{kg}$. Approximately 204 random positions of the barrier are considered in the MAT2D model and for each random position; the maximum length, width and the time of remediation to reach the desired goal of $1 \mathrm{mg} / \mathrm{l}$ are evaluated. The length and width of the barrier in each case is calculated next. Further, a large data set comprising length, width and remediation time for all the 204 locations generated by the numerical model (MAT2D), are later replaced with an Artificial Neural Network (ANN) model to achieve faster computations.

Furthermore, the ANN is coupled with a search based evolutionary optimization algorithms developed in this study to optimize the overall cost and remediation time. For complete management of groundwater, two different ANN models are adopted. The first ANN model is trained by considering length and width of the PRB as inputs and the time of remediation as a target. Data sets provided to the first ANN model are obtained by running the MAT2D model. Out of the total 204 data sets, 103 data sets are used for training purpose whereas the remaining data is divided into two parts; for testing and validation. After validation, it is found that the first ANN model performed better than the MAT2D model and thus can be used as an alternate model.

Similarly, the second ANN model is developed to predict the distance of the barrier from the source with the provided length and width of the barrier design as an input. Hence, the distance of the barrier from the source is considered as a target parameter for ANN modelling. The data sets of the length, width and distance of the barrier provided to the second ANN model were earlier obtained from MAT2D. Subsequently, two optimization codes are developed in this study by combining 4 different optimization algorithms namely; Non-Dominated Sorting Genetic Algorithm (NSGA) (Deb et al. [18]), Particle Swarm Optimization (PSO) (Kennedy and Eberhart [19]), Simulated Annealing (SA) (Kirkpatrick et al. [20]) and Differential Evolution (DE) (Storm and Price [21]). The first code is developed by combining DE, PSO and NSGA whereas the second code is developed considering DE, PSO and SA instead of NSGA.

Later, the trained first ANN model is coupled with both these optimization codes and evaluated for different population sizes. The multi-objective problem involving the cost associated with the installation of barrier and the time of remediation required for full restoration is solved using the developed simulation-optimization algorithms. The upper and lower bounds of length, width and time are provided to the model and the penalty method is used for handling the constraints. The length of the barrier is taken between $6 \mathrm{~m}$ and $56 \mathrm{~m}$ with the associated width between $38 \mathrm{~m}$ and $74 \mathrm{~m}$ respectively. The minimum and maximum times for remediation assumed for the model are 2.5 years and 10 years respectively. Further, the program evaluated for different set of population sizes yields the Pareto of the cost and remediation time.

Later, both the optimization-simulation coupled codes are compared for their performances using two different performance analysers namely Inverse Generational Distance (IGD) and spread. IGD and Spread indicates the convergence and divergence behaviour of the algorithm, respectively. Hence, from the performance analysis, it is found that the first code converged and diverged very well as compared to the second code and thus the Pareto chart of cost and remediation time (two objectives) generated for the population size 100 is considered as the final solution (Fig. 8). 


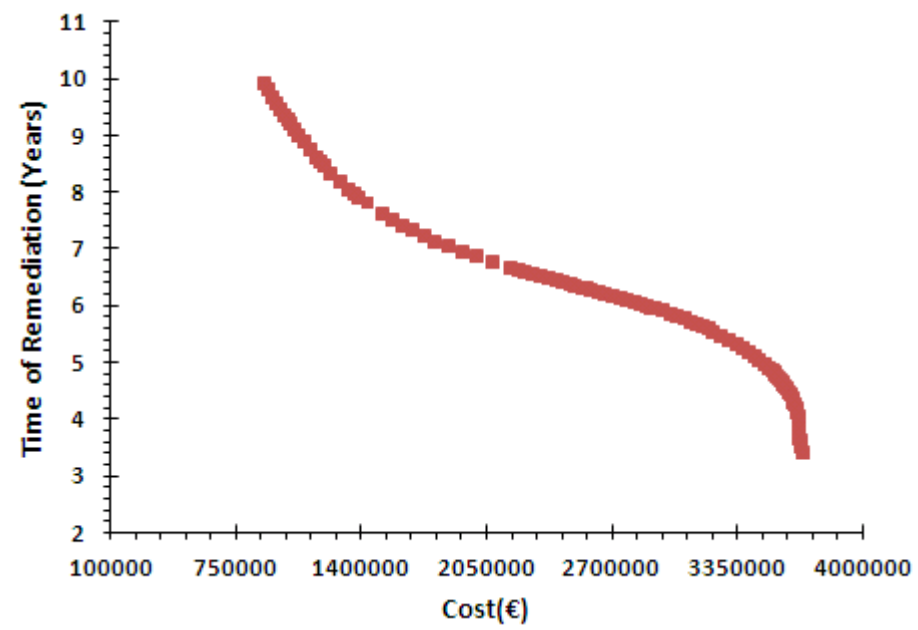

Figure 8: Pareto of cost and time of remediation for population size of 100.

Finally, after finding the 100 sets of optimal values of time of remediation and cost, the set of optimal length and width are also determined from the first simulation-optimization model. The distance of the barrier from the source for these optimal lengths and widths of the barrier is determined next using the second ANN model. Furthermore, among the 100 set paretos, a post pareto approach namely fuzzy logic is used to determine the best optimal solution. Finally, the value of maximum linear membership function determined using fuzzy logic approach provide the best optimal values of the cost $(€ 1,433,540)$, time of remediation (7.799 years), optimal length and width of the barrier $(11.13 \mathrm{~m}$ and $70.26 \mathrm{~m})$ as well as the optimal distance of the barrier from the source (176.42 m).

\section{CONCLUSIONS}

From the design curves of PRB generated for removal of contaminants, one can also determine the required length and width of the barrier and the relevant cost if the source concentration is known. The simulation-optimization approach used to clean-up contaminated groundwater by optimizing a permeable reactive barrier design is a unique concept. Thus, through minimizing two objectives (cost and time of remediation) simultaneously, a set of 100 best solutions of the length, width and location of the barrier from the source (that needs to be installed) are obtained. Moreover, fuzzy logic approach suggested the best optimal solution for final decision making.

\section{REFERENCES}

[1] Morrison, S.J. \& Spangler, R.R., Chemical barriers for controlling groundwater contamination. Environmental Progress, 12(3), pp. 175-181, 1993.

[2] McMurtry, D.C. \& Elton, R.O., New approach to in-situ treatment of contaminated groundwater. Environmental Progress, 4(3), pp. 168-170, 1985.

[3] Kurniawan, T.A., Chan, G.Y., Lo, W.H. \& Babel, S., Physico-chemical treatment techniques for wastewater laden with heavy metals. Chemical Engineering Journal, 118(1), pp. 83-98, 2006. 
[4] Babel, S. \& Kurniawan, T.A., Low-cost adsorbents for heavy metals uptake from contaminated water: a review. Journal of Hazardous Materials, 97(1), pp. 219-243, 2003.

[5] Hunt, R.J., Anderson, M.P. \& Kelson, V.A., Improving a Complex Finite-Difference Ground Water Flow Model Through the Use of an Analytic Element Screening Model. Ground Water, 36(6), pp. 1011-1017, 1998.

[6] Budge, T.J. \& Sharp, J.M., Jr., Modeling the usefulness of spatial correlation analysis on Karst systems. Ground Water, 47(3), pp. 427-437, 2009.

[7] Mantoglou, A., Pumping management of coastal aquifers using analytical models of salt water intrusion. Water Resources Research, 39(12), pp. 1-12, 2003.

[8] Gaur, S., Chahar, B.R. \& Graillot, D., Analytic elements method and particle swarm optimization based simulation-optimization model for groundwater management. Journal of Hydrology, 402(3), pp. 217-227, 2011.

[9] Cheng, A.H.D., Halhal, D., Naji, A. \& Ouazar, D., Pumping optimization in saltwaterintruded coastal aquifers. Water Resources Research, 36(8), pp. 2155-2165, 2000.

[10] Vedula, S., Mujumdar, P.P. \& Sekhar, G.C., Conjunctive use modeling for multicrop irrigation. Agriculture Water Management, 73(3), pp. 193-221, 2005.

[11] Ko, N.Y., Lee, K.K. \& Hyun, Y., Optimal groundwater remediation design of a pump and treat system considering clean-up time. Geosciences Journal, 9(1), pp. 23-31, 2005.

[12] Aziz, A. \& Wong, K., A neural-network approach to the determination of aquifer parameters. Ground Water, 30(2), pp. 164-166, 1992.

[13] Rifai, H.S., Newell, C.J., Gonzales, J.R., Dendrou, S., Kennedy, L. \& Wilson, J.T., BIOPLUME III Natural Attenuation Decision Support System Version 1.0 User's Manual, Air Force Center for Environmental Excellence, Brooks AFB: San Antonio, TX, 1997.

[14] Wilson, J.L. \& Miller, P.J., Two-dimensional plume in uniform ground-water flow. Journal of the Hydraulics Division, 104(4), pp. 503-514, 1978.

[15] Burger, C. \& Finkel, M., Performance of multiple gate funnel-and-gate systems in three-dimensional, anisotropic, heterogeneous aquifers. IAHS PUBLICATION, 298, p. 125, 2005.

[16] Bürger, C.M., Bayer, P. \& Finkel, M., Algorithmic funnel-and-gate system design optimization. Water Resources Research, 43(8), pp. 1-19, 2007.

[17] Bowman, R.S., Surfactant-altered zeolites as permeable barriers for in situ treatment of contaminated groundwater. Proc. Industry Partnerships to Deploy Environmental Technology Meeting, pp. 22-24, 1996.

[18] Deb, K., Agrawal, S., Pratap, A. \& Meyarivan, T., A fast and elitist multi-objective genetic algorithm: NSGA-II. Technical Report, Indian Institute of Technology, Kanpur, Kanpur Genetic Algorithm Laboratory, 2000.

[19] Kennedy, J. \& Eberhart, R., Particle swarm optimization. Proceedings of the International Conference on Neural Networks, Australia IEEE, pp. 1942-1948, 1995.

[20] Kirkpatrick, S., Gelatt, C.D. Jr. \& Vecchi, M.P., Optimization by simulated annealing. Science, 220(4598), pp. 671-680, 1983.

[21] Storm, R. \& Price, K., Differential evolution - a simple and efficient heuristic for global optimization over continuous spaces. Journal of Global Optimization, 11(4), pp. 341-359, 1997. 